\title{
PROBLEMS OF IRRIGATING GRASSLAND IN CANTERBURY
}

\author{
By C. HILGENDORF, Sherwood, Mid-Canterbury.
}

There are four irrigation schemes at present in Canterbury: two small ones at Redcliffe and Levels and two larger ones at Mayfield-Hinds and AshburtonLyndhurst. The latter two cover 48,000 and 58,000 acres. I intend to restrict my discussion of the problems of irrigating grassland in Canterbury to that part of the province covered by the Lismore silt loam with a water table seldom rising above $50 \mathrm{ft}$, and with a 25 to $35 \mathrm{in}$. rainfall, relatively well distributed, though with a high summer evaporation. This does not take in all the present schemes which contain some more fertile land, but it and similar soil types cover by far the greater part of both present and suggested schemes.

Having limited the subject in this way it appears there is only one major problem, i.e., that it is costly, particularly in relation to the immediate product being grown, which is, of course, grass.

The great difficulties encountered on some irrigation schemes such as the precipitation of alkali salts and drainage troubles have not appeared on irrigated farms here. There can, however, be a drainage problem on naturally poorly drained land below an irrigation scheme. The amount of leaching seems to be remarkably small, certainly no more than, if as much as, on similar land with a high rainfall.

In fact, the whole picture of irrigated land in Canterbury is very like suddenly increasing the rainfall, apart, of course, from the cost and certain mechanical difficulties of distribution. Some people look on irrigation water as a kind of elixir of life ; others as a concentrated brand of prussic acid. To me it seems very like ordinary rain, but dearer. It should, however, be noted that inch for inch irrigation water is less effective than rain. This is partly because more irrigation water is lost through drainage, and partly because irrigation usually takes place in conditions of 
high evaporation. An inch of rain normally keeps the soil moist for longer than an inch of irrigation water.

Most of the problems which have faced farmers starting irrigation have been difficulties of adjusting themselves to conditions of higher rainfall and higher pasture production. By and large, stock certainly thrive less well under irrigation, but only to the extent that high carrying capacity often brings increased troubles and to the extent that sheep are not well designed to cope with very lush pastures, and more particularly with pure pastures of perennial ryegrass and white clover. Ryegrass-white clover pastures thrive particularly well under irrigation and there was initially a trend towards this type from a more mixed one typical of Canterbury.

Foot-rot has become a more constant if not a greater nuisance. There has been a tendency to change from half-bred and Corriedale sheep to Romneys, with some attendant difficulties of supply. There are considerably more cattle being carried and here the problem has been to get a comparable return from an animal producing only meat instead of meat and wool, especially on a falling market. But none of these difficulties is in any way peculiar to irrigation.

The irrigator has some difficulties of distribution which he may legitimately claim are all his own. The maintenance of distributing races and head ditches is proving a good deal more burdensome than was expected. Efficient maintenance is of quite exceptional importance, since internal races often extend to a mile or more. Loss of water at junctions, headgates, and overflowing ditches can easily waste half the water coming out of the turn-out. It would be quite rare for all the water supplied to be available where it is required. This is obviously wasteful of both water and labour.

Among the reasons for water loss are inefficiently constructed head ditches, badly fitting junction gates and head gates, and excess growth in ditches. By far the greatest reason, and one which contributes to most of the others, is, however, the silting up of ditches. This is sometimes due to scouring in the farmers' own race and the consequent filling up of a race lower down; much more often it is due to sand (not silt) brought down by the irrigation water. The Ministry of Works has some trouble with this sand in its own races, but most of it remains in suspension (because of the constant velocity of the races) until it is dropped in an 
area of dead water in the farmer's race. At the moment this silting does not affect all farmers; on the other hand it has become progressively worse over the last few years. It is not yet a major problem, but might become one. I remember reading somewhere that the decay of civilisation in Mesopotamia was ultimately due to inability to keep the irrigation canals free of silt.

Last season I took many hundreds of tons of sand from my races and unless the Ministry of Works can trap the sand near the headworks there seems no real solution. My own attempt at amelioration is to dig ponding areas near turn-outs. These trap the sand in .one place instead of spreading it through the whole race system and means it can be cleaned out more easily; but we may have some very considerable hills in say 100 years;

However, I have said that the one major problem facing irrigation farmers in Canterbury is that irrigating is expensive in relation to the value of the crop grown, and any other problems are comparatively trivial. Any solution obviously enough depends either on raising the value of the crop or reducing costs.

Virtually the only crop watered is pasture, whether it be grass or lucerne. Heavy watering appears, on the average, to a little more than double the measured dry matter yield and to a little less than double the sheep carrying capacity. This build-up takes place quite quickly-in 2 or 3 years-and after that progress has been disappointing. It might have been thought that dairy cows would utilise irrigated grass more efficiently than sheep, but the Department of Agriculture at Winchmore reached $1601 \mathrm{~b}$ of butterfat per acre (again with very heavy watering), but made no further progress.

But perhaps we should be irrigating something which is more immediately valuable than grass. After all, by far the most extensively irrigated crop in the world is rice-as much as all the other crops put together. But New Zealand grows most crops rather poorly compared with pasture. The only other product with which we can sometimes compete on the world's markets is herbage seeds and these are not so far conspicuously successful under irrigation.

When I speak of the cost of irrigation being high I do not refer initially to the cost of the water itself, but to the cost of preparing land and applying water: it is made up something like this : 
Border diking . . . $50 \begin{array}{rrr}5 & 0 & 0\end{array}$

Installing headgates and concrete checks ${ }^{\prime} \cdot{ }^{\prime} \quad . \quad 1100$

Loss of land to M.O.W. and access crossings . $\quad 100$

Labour-6 waterings at $1 \frac{1}{2}$ acres per Per acre

hour at $6 /-$ per hour
(These are M.O.W. figures)

Truck or tractor and trailer at 10/-

a day 'and Depreciation only) $=4 /-$ per year

Maintenance and cleaning of head-'

races, headgates, etc. . . $=\begin{gathered}3 /- \text { per year } \\ \text { Capitalised }\end{gathered} 300$

(My own cost is more than double this.)

Irrigation sheets and headgate

boards

Cost of rebordering at $£ 2$ per acre $\quad=1 /$ Capitalised spread over 20 years.

No account is taken of other costs such as fencing, stockwater, reticulation, new buildings, and housing and extra stock, as these are common to any developmental process and are not directly attributable to irrigation.

The present value of the type of land we are discussing, before preparation for irrigation, might be $\$ 35$ per acre. So if someone wishes to buy a farm he can buy say 500 acres of irrigated land or 1000 acres and farm it dry or 500 acres of $£ 70$ an acre land and his annual charges (apart from normal farm expenses) will be much the same whether they are made up predominantly of interest or labour costs. This takes no account of the cost of water. If the cost, as the Ministry of Works suggests for a new scheme, is to be something over 20 s. per acre watered, then the prospective farmer could buy $2 \frac{1}{2}$ times as much land or the same area at $2 \frac{1}{2}$ times the price.

However, costly or not, we already have some irrigation schemes and $m \& y$ have more so we must make them go as well as possible. The obvious line of attack is to try to reduce costs and equally obviously the cost of labour for watering is the first one to choose. Almost everyone who looks at an irrigation scheme thinks it should be possible to design an automatic irrigation system. Well it is possible, though not as easy as it looks, and there are several devices in operation. I do not, myself, think they will reduce 
costs much, though they may come into common use as a method of saving labour when it is difficult to obtain.

In the first place none of the systems so far designed is automatic in the sense that one can sit at home and operate it; and there is still a considerable amount of labour required. None of them is applicable, on most farms, to more than a portion of certain fields. They are all costly in varying degrees to install. And lastly they are inefficient. Either land is left unwatered or a great deal of water is wasted. A man watching the flow all the time is very lucky if he can turn off the water at a headgate so that one check is completely watered and no more. To efficiently water a group of checks is a good deal more difficult since no two water alike-and automatic irrigation assumes watering in groups. There are also other variables: varying rates of supply from the turn-out; varying losses in distributing races; varying lengths of pasture, and varying soil moisture. If the field is to be even moderately completely watered by automatic irrigation, one must count on a very considerable amount of surplus water at the lower end, and this surplus water tends to get into some inconvenient places. So although I am willing to be convinced, I doubt if automatic irrigation is at present the answer.

If some surplus water can be dealt with, a more practical method of saving labour costs is to wild-flood some fields from a contour head-ditch. If the head-. ditch is well constructed, from $1 / 3 r d$ to $2 / 3 r d s$ of the paddock can usually be watered with very little moving of sheets. If some preliminary levelling was carried out before sowing down, a higher proportion might be possible. This method has some other advantages: it saves not only the cost of labour for watering but the cost of bordering and headgates and the great inconvenience of border diked paddocks. Stock, in my experience, thrive best when they have access to both dry and irrigated pasture. It is certainly very convenient to have some paddocks where sheets, with a little ingenuity, need only be moved every 4 or 6 hours ; it greatly simplifies night watering and watering at particularly busy periods.

Since water is an expensive commodity by the time it is on the land, irrespective of the price paid for it, another line of thought is that perhaps we can use less of it. After all, the New Zealand farmer, who is normally a realist, does not use sulphate of ammonia, which is also an expensive commodity, to grow extra 
grass in October-November or in the middle of winter. If he uses it at all, it is to grow grass in the early spring when nitrogen gives a reasonable effect and when the grass is particularly valuable. In the same way a single irrigation is much more effective at some seasons than others and moreover the grass grown is much more valuable at some seasons than others.

Hitherto, the tendency has been to assume that the more water one used the better it paid, and if the pattern of grass growth did not suit our farming system then the system had to change. For instance, if we could grow a lot of grass in January-February and the sheep do not need it then, we had to look round for some means of utilising it. Possibly dairying was the answer. We tried running more beef cattle; we ran more ewe lambs and bought wether lambs for fattening; we made hay in January-February. But in average seasons none of these projects is very profitable. At the same time, some of us began to realise that the grass we grew in the late summer was expensive and last summer convinced us it was very expensive. To keep grass growing vigorously last January it had to be watered every ten days ; if it was ryegrass, perhaps even more often. The grass I grew last summer is the dearest I have ever grown or ever hope to grow.. At the same time other factors increased our suspicion that intensive mid-summer watering might not be advantageous. Though the Ashburton-Lyndhurst scheme is rather less than half developed it was already, at this period, using more water in the daytime than it was designed for, as well as a lot at night. So with full development the water would be in short supply. Further, it is unlikely that even future schemes could be designed economically to supply water at 10 daily intervals. Another point has influenced my own thinking. It is, of course, true that by watering intensively right through the season the highest pasture yield is obtained. On the other hand, I believe a higher yield for March, April, and May is obtained if the field is not watered or only lightly watered during January and the first half of February.

So it looks to me as though we might go back to watering intensively only at those times when we need extra grass in our usual Canterbury sheep farming programme. In a normal season, and of course a normal season is just as rare here as it is in England or Australia (but it is just as well to have a plan to cover one), our periods of intensive watering might be something like this. Water in the late spring or early sum- 
mer to keep the grass going till most of the lambs are away. (December has' always been a critical month on the Plains.) Water again from mid-February onward ; first to produce flushing feed for the ewes and then to set the autumn-saved grass going. Watering at other times need only be enough to overcome droughts at unusual 'times (as we nearly had. this spring) and to produce the minimum necessary feed in the middle of summer..

I believe irrigation has an important role to play in Canterbury only if its costs can be kept low.

Many of our costs in New Zealand are high by overseas standards ; unless we can continue to grow grass cheaply we shall have great difficulty in competing in overseas markets. 